\title{
A phase model for the low-carbon transformation of energy systems in the MENA region
}

\author{
Manfred Fischedick ${ }^{1} \cdot$ Georg Holtz $^{1}$ (i) $\cdot$ Thomas Fink $^{1} \cdot$ Sarra Amroune $^{1} \cdot$ Franziska Wehinger $^{2}$
}

Received: 19 July 2019 / Accepted: 15 June 2020 / Published online: 30 June 2020

(c) The Author(s) 2020

\begin{abstract}
Given large potentials of the MENA region for renewable energy production, transitions towards renewables-based energy systems seem a promising way for meeting growing energy demand while contributing to greenhouse gas emissions reductions according to the Paris Agreement at the same time. Supporting and steering transitions to a low-carbon energy system require a clear understanding of socio-technical interdependencies in the energy system as well as of the principle dynamics of system innovations. For facilitating such understanding, a phase model for renewables-based energy transitions in MENA countries, which structures the transition process over time through the differentiation of a set of sub-sequent distinct phases, is developed in this article. The phase model builds on a phase model depicting the German energy transition, which was complemented by insights about transition governance and adapted to reflect characteristics of the MENA region. The resulting model includes four phases ("Take-off renewables", "System integration", "Power to fuel/gases", "Towards 100\% renewables"), each of which is characterized by a different cluster of innovations. These innovations enter the system via three stages of development which describe different levels of maturity and market penetration, and which require appropriate governance. The phase model has the potential to support strategy development and governance of energy transitions in MENA countries in two complementary ways: it provides an overview of techno-economic developments as orienting guidelines for decision-makers, and it adds some guidance as to which governance approaches are suitable for supporting those developments.
\end{abstract}

Keywords Transition $\cdot$ Electricity $\cdot$ Renewable energy $\cdot$ Middle East $\cdot$ North Africa

\section{Introduction}

Countries of the Middle East - North Africa (MENA) region intend to find ways to develop their energy systems into lowcarbon systems since sixteen countries from the region, by signing the Paris Agreement in April 2016, joined the global efforts to mitigate climate change. ${ }^{1}$ Many countries in the region correspondingly have set ambitious goals and developed plans to scale up renewable energy production and to limit greenhouse gas (GHG) emissions. The clearest vision is probably present in the United Arab Emirates (UAE). The "UAE National Energy Plan 2050" 2 strives for an increase

Georg Holtz

georg.holtz@wupperinst.org

1 Wuppertal Institute for Climate, Environment and Energy, Döppersberg 19, 42103 Wuppertal, Germany

2 Friedrich-Ebert-Stiftung (FES), Hiroshimastraße 17, 10785 Berlin, Germany of renewable clean energy to $44 \%$ by 2050 and a reduction of $\mathrm{CO}_{2}$ emission by $70 \%$ in the same time frame. Among the Nationally Determined Contributions (NDCs) formulated by Arab states in the context of the Paris Agreement [1], the NDCs of Morocco, Jordan and Algeria, for example, mention targets for increasing the shares of renewable energy in the countries energy mixes.

Those goals have to be achieved against the backdrop of a rapidly growing population in the Arab Region, which is projected by some to increase by two-thirds until $2050 \mathrm{com}$ pared to 2010 [2] and other factors-including industrialisation, water desalination and increasing use of electricity for cooling — which induce trends towards substantially higher

\footnotetext{
1 The Paris Agreement has been signed by Algeria, Bahrain, Egypt, Iran, Israel, Jordan, Kuwait, Lebanon, Libya, Morocco, Oman, Quatar, Saudi Arabia, Tunisia, United Arab Emirates and Yemen (https:// treaties.un.org).

${ }^{2}$ https://government.ae/en/about-the-uae/strategies-initiatives-andawards/federal-governments-strategies-and-plans/uae-energy-strat egy-2050 (last accessed: June 2020).
} 
Fig. 1 Approach for the development of the phase model for energy transitions in MENA countries

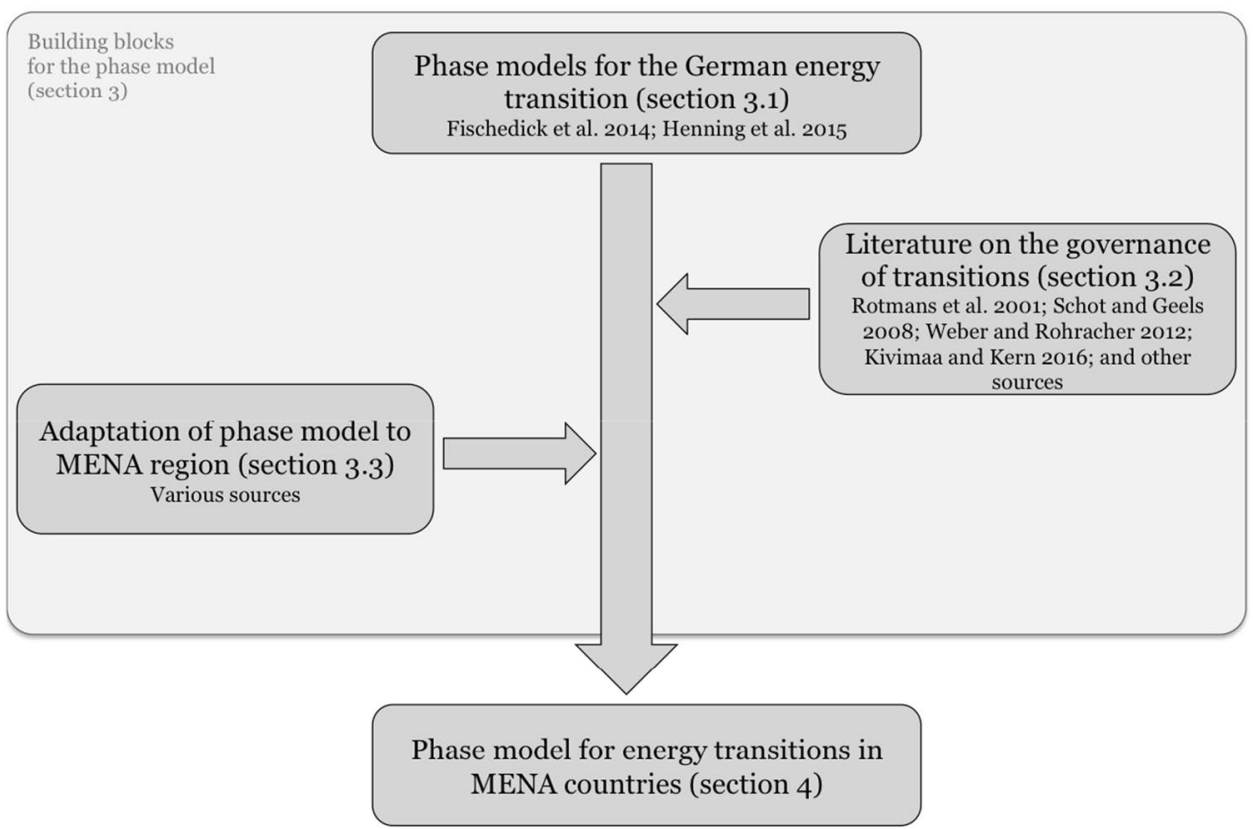

overall domestic energy demands in MENA countries [3] (see "Differences between model assumptions and characteristics of the MENA region").

The region is endowed with huge potentials for renewable energy, in particular wind and solar power, that provide opportunities for nearly $\mathrm{CO}_{2}$-free electricity production and economic prosperity (see "Differences between model assumptions and characteristics of the MENA region"). Transitions towards renewables-based energy systems, therefore, seem promising for meeting growing energy demand while contributing to GHG emissions reductions at the same time.

A transition towards a renewables-based energy system involves large-scale deployment of renewable energy technology, the development of enabling infrastructure, the elaboration of appropriate regulatory frameworks and the creation of new markets and industries [4-6]. The long-term governance of a transition across these different domains requires a clear understanding of socio-technical interdependencies in the energy system as well as of the principle dynamics of system innovations [7-9]. Thus, the availability of useful conceptual frameworks for describing energy transition processes is a prerequisite for fostering and steering transitions to renewables-based energy systems in MENA countries.

The objective of this paper is the presentation of such a conceptual framework in terms of a "phase model" for energy transitions towards renewables-based low-carbon energy systems in MENA countries. The phase model provides an overall framework which structures the process of the energy transition over time through the differentiation of a set of subsequent phases. The phases are defined by main elements and processes shaping each phase, and qualitative differences between phases are highlighted. As such, the phase model provides an overview of a complex transition process and facilitates the early-on development of policy strategies and policy instruments according to the requirements of the different phases.

\section{Methods}

The phase model for energy transitions towards renewables-based low-carbon energy systems in MENA countries presented in this article was developed through the integration and synthesis of different strands of literature (Fig. 1). It builds on a phase model that has previously described the transformation of the German energy system towards a decarbonized energy system based on renewable energies $[10,11]$ (see "The starting point: the phase model for the German energy transition").

The phase model for the German energy system is complemented with insights from the field of sustainability transitions research (see "Governing transitions: insights from sustainability transitions research"). This strand of literature focuses on the dynamics of fundamental long-term change in societal subsystems such as the energy system. Its perspective provides insights into the governance of long-term change in energy systems in different phases that complements those provided by the phase model presented in [10, $11]$.

The phase model of Fischedick et al. [10] and Henning et al. [11] has been developed for the German context and thus requires adaptation to the MENA countries. 
Characteristics that distinguish MENA countries from Germany with regard to the energy system are discussed in "Differences between model assumptions and characteristics of the MENA region". Based on this analysis, the phase model is adapted to MENA countries in "Adaptation of model assumptions to characteristics of MENA countries".

The phase model for energy transitions towards renewables-based low-carbon energy systems in MENA countries derived from these various strands of literature is presented in "A phase model for the MENA Region".

\section{Building blocks of the phase model for MENA countries}

\section{The starting point: the phase model for the German energy transition}

The phase model of Fischedick et al. [10] and Henning et al. [11] defines four phases to structure the (envisioned) German energy transition towards a renewables-based energy system. Main assumptions underlying these phases are deduced from fundamental characteristics of renewable energy sources, as summarized in the following.

\section{Socio-technical interdependencies in the energy system}

Scenario studies such as $[12,13]$ assume that in most countries, including the MENA countries, the bulk of the energy used in a future renewables-based energy system needs to be provided by wind and solar sources, while the contribution of other sources such as biomass and hydropower cannot be significantly increased due to unavailability, limitations of potential and competition with other uses of biomass (food crops, animal forage, fibre, forestry products) and nature conservation. ${ }^{3}$ In agreement with these studies, a basic assumption of the phase model, therefore, is that the share of electricity from wind and solar sources in the energy mix will significantly increase. This includes the direct utilization of electricity in end-use sectors that have so far relied on fossil fuels and natural gas, in particular e-mobility in the transport sector and the utilization of heat pumps in the building sector. Emission reduction via direct utilization of electricity is technologically difficult to achieve in some sectors, such as aviation, marine and heavy-duty vehicles and the provision of high-temperature heat for industry. Possible substitutes for fossil fuels and natural gas in those sectors

\footnotetext{
${ }^{3}$ Certainly, there are some exceptions. For example, countries like Iceland and Ethiopia can make use of geothermal resources while countries like Austria and the Scandinavian countries have huge hydropower potentials.
}

are hydrogen and hydrogen-based synthetic fuels and gases (power-to-fuel/power-to-gas). The required hydrogen can be gained from renewable electricity via electrolysis.

The strong role envisioned for electricity in the future energy mix requires to pay special attention to the electricity infrastructure. A crucial technical characteristic of this infrastructure is that the feed-in and extraction of electricity from the grid always needs to be in balance to maintain grid stability. This implies that power production and demand need to be synchronized, or storage is required. Storage of electricity requires sophisticated technical equipment and the cheapest option (pump storage) requires suitable geographical conditions. In most countries of the world, electricity cannot simply be stored in large amounts. Thus, a mix of different flexibility options is typically required to match the volatile supply of solar and wind power plants with electricity demand. Flexibility can be ensured through extending grids over larger areas to balance regional variation in the supply of wind and solar radiation, increasing flexibility of the residual fossil-based power production, storage, and demand-side management [14]. Furthermore, flexibility management requires intensified communication between system components via information- and communication technologies (ICT).

The stronger coupling of sectors through direct utilization of electricity in the heat and mobility sectors and through the usage of power-to-fuel/power-to-gas solutions requires an alignment of rules and regulations between those sectors ${ }^{4}$ and the build-up of infrastructure (e.g., charging stations for e-mobility and hydrogen infrastructure). Furthermore, the low operational costs and the volatility of supply of wind and solar electricity pose considerable challenges to current market designs. ${ }^{5}$ Therefore, a new market design might be required to accommodate large shares of volatile renewables [15].

The electricity demand induced by direct utilization of electricity in the heat and mobility sectors and through the usage of power-to-fuel/power-to-gas solutions would be

\footnotetext{
${ }^{4}$ In the past, rules and regulations often have been defined independently per sector, and fees and taxes have been introduced for various reasons, including: refinancing the promotion of particular measures /technologies (e.g., surcharge for renewable energy), refinancing infrastructure costs, steering measures due to environmental considerations, and other economic, political and social considerations (e.g., reduced fees for industry to maintain competitiveness). As a result, fees and taxes partly differ strongly for different energy carriers, even if the energy is used for the same purpose.

${ }^{5}$ Electricity supply from wind and solar power sources depends on weather conditions. Consequently, favourable conditions lead to high amounts of feed-in from many plants at the same time, which in combination with low operational costs results in very low market prices. On the other hand, during times of low supply that is barely able to meet basic demand, market prices might become very high.
} 
four or five times higher than the current power demand and would exceed the renewable energy potential of the country by a factor of two or even three $[16,17]$. To counterbalance this, energy scenarios indicate that energy efficiency improvements and an overall reduction of primary energy need to almost half of today's level are a strong prerequisite for fulfilling energy transition targets.

\section{Phases of the phase model}

The outlined socio-technical interdependencies have been condensed by $[10,11]$ into a phase model with four phases that provide a temporal order of developments that build upon each other and jointly lead towards a fully renewablesbased energy system. Broadly summarized, the phases follow this sequence:

1. In a first phase, renewable energy technologies (particularly photovoltaic and wind energy plants) are developed and introduced into the market. These developments are triggered by dedicated R\&D programs and first market introduction policies. Market introduction has no major effects on the rest of the energy system, yet. Initial strong cost-reductions for the application of those technologies are achieved.

2. The further expansion of renewable electricity supply and usage in the second phase requires measures for the integration of renewable electricity into the energy system, including flexibility of the residual fossil power production, build-up and integration of storage, and activation of demand side flexibility. This already includes some coupling between the power system with the heat and mobility systems (power-to-heat, e-mobility). Cross border capacity extensions provide additional flexibility via power exchange with neighbouring countries, and distribution grids need to be retrofitted to accommodate increased decentralized feed-in of electricity.

3. The third phase starts when the further increasing share of renewables creates the need for long-term storage of renewable electricity to balance periods during which supply from volatile sources significantly exceeds demand. For Germany, energy model results indicate that a substantial demand for long-term storage will emerge when the share of renewable energies in the electricity generation mix exceeds $70 \%$ [18]. Another driver for the third phase is an increasing pressure on the enduse sectors to massively reduce the use of fossil fuels, for example driven by strict sector-specific greenhouse gas mitigation targets. Power-to-fuel and power-to-gas technologies become integral parts of the energy system and the associated infrastructure needs to be developed. Imports of renewables-based energy carriers (electricity, hydrogen, synthetic fuels/gases) gain importance.
Market structures need significant adaptation if marginal costs of the dominant electricity source are close to zero, and appropriate incentives have to be provided to secure power system stability and a sufficient backup system.

4. In the final phase, the residual fossil fuels become fully replaced in all sectors, including sectors that are difficult to decarbonize such as specific industries (e.g., cement and glass production) and aviation.

Throughout all phases, the capacities for renewable electricity supply need to be further expanded to meet increasing demands from other sectors and from power-to-fuel/gas applications. Furthermore, as outlined above, energy efficiency needs to be considerably increased.

Certainly, there is no strongly determined switch from one phase to the other, but a rather smooth change can be observed with some sub-regions entering the next phase earlier and others later. However, for Germany as a whole, phase 1 can be assumed to be completed [11, 19], and the country entered the second phase in the first half of the 2010s.

\section{Governing transitions: insights from sustainability transitions research}

Transitions such as the one towards a renewables-based energy system envisioned by the phase model outlined above cannot be perfectly steered nor completely predicted and controlled. The reasons are the involvement of many actors, the high level of interdependency of many different processes, and the fundamental uncertainty associated with technological, economic and socio-cultural developments $[8,9,20]$. Sustainability transitions research is a research field that aims to increase the understanding of fundamental long-term ${ }^{6}$ change in sectors such as energy and transport and to provide advice for governing these processes towards sustainability targets. The field has emerged at the intersection of innovation studies, science and technology studies, evolutionary economics and history of technology [22, 23]. Transition researchers typically apply inter- and trans-disciplinary approaches to analyse systemic aspects that arise from the interrelatedness of processes in the dimensions of technology, institutions, ${ }^{7}$ policy, actor networks, infrastructure, and society.

\footnotetext{
${ }^{6}$ In historical cases, transitions typically took several decades. In envisioned sustainability transitions, change arguably needs to occur faster on larger scales than has been observed historically [21].

7 'Institutions' here refers to the sociological meaning of the term, i.e., formal and informal rules and regulations that structure and give meaning to social life (i.e., it does hence not refer to the meaning of the term in the sense of organizations).
} 
It is far beyond the scope of this article to discuss the governance of transitions at length. In the following, we present and synthesize some main findings that are used as a basis for the development of the phase model for the MENA region in "A phase model for the MENA Region".

\section{The multi-level perspective}

One of the most prominent frameworks used by transition researchers is the 'multi-level perspective' (MLP) [24-26]. The MLP provides a baseline understanding of transitions. As such, it facilitates the conceptualization of transition dynamics and provides a basis for the development of governance measures.

The MLP suggests that fundamental change is the result of the interplay of developments at three analytical levels. The 'regime' level captures the socio-technical system that dominates the sector of interest (i.e., in our case: the energy sector). The regime is constituted by the application of certain technologies, the existence of (large-scale) infrastructure that facilitates technology use, institutions that regulate the sectoral activities, a broad set of supportive auxiliary technologies and institutions (e.g., the possibility to contract insurances), and actors that perform different roles in the sector's value chain (e.g., technology provider, producer, regulator, intermediary, consumer). The main idea of the regime concept is that the regime is stabilized through various self-reinforcing mechanisms and lock-ins. Those include economies of scale and network effects, long lifetimes of some of the material components, cognitive heuristics that, e.g., shape engineers' perspectives and thus technological development, business models that are tailored to the existing value chain, the social significance of the system, regime actors' linkages to political power, routine behaviour and comfort that relies on these systems, and societal expectations and norms of conduct. Moreover, the regime components have co-evolved over long periods of time and have become increasingly intertwined [27]. Due to their interrelatedness, radical change of single components is not feasible without affecting other, connected components. Therefore, regime change tends to follow incremental development pathways, and fundamental change is hampered.

'Niche innovations', located at the niche level, are structurally similar to regimes in that they provide the same kind of service or function to society and consist of the same kind of interrelated components as regimes. However, they are radically different from regimes regarding the specific components themselves (e.g., technologies deployed). They are less mature and smaller (e.g., in terms of market size and number of actors involved), but gain a foothold and evolve in particular geographical areas or market niches, or with the help of targeted policy support.
Finally, the 'landscape' level includes slowly changing, pervasive trends (such as demographic shifts, climate change) as well as more short-term shocks that affect the regime and niches, such as disasters (e.g., the FukushimaDaiichi accident or bushfires in Australia), economic crises, and wars. A major defining characteristic of landscape developments is that they cannot be (significantly) influenced by regime or niche actors but constitute some external context that fosters some developments on the regime and niche levels while hampering others.

The interconnected and self-stabilizing character of the regime implies that fundamental change does not happen through single innovations, but (only) through dynamics at the level of competing and mutually influencing systems (regime, niches). According to the MLP, transitions come about if both (a) the regime is under pressure from landscape developments, and (b) niches exist which put pressure on the regime and provide alternative solutions. Transitions may occur along various pathways of landscape-regime-niche interactions [28, 29], but the constitutive result of a transition is the substitution of a regime by a former niche, or a fundamentally changed regime.

It is important to note that the MLP 'levels' are not of geographical but of analytical nature, and that the MLP can be applied to different empirical levels [30].

\section{Three stages of transitions: Niche formation, Break-through and Market-based growth}

Early transition governance approaches, and in particular the strand of 'strategic niche management' [20,31], has focussed on understanding and supporting the development of niches, as their existence constitutes an essential precondition for fundamental change. Recent literature on the governance of transitions adds to this and emphasizes the flip-coin-i.e., policies for 'creative destruction' [32] or 'exnovation' [33] of persisting regime components, such as cutting R\&D support for regime technologies or implementing pollution taxes. Putting pressure on the regime is argued to be important especially for later stages of the transition process when niche innovations have gained some momentum. The role of policy mixes is analysed in this literature as well, and it is suggested that single policy instruments are insufficient to orchestrate the multiple developments that jointly drive a transition.

For providing and overview of the multiplicity of policy measures and their potential role for transitions, we build on the above mentioned literature (in particular: [7, 31, 32, 34]) for distinguishing three stages of transitions and associated policy approaches: 'niche formation', 'break-through' and 'market-based growth'.

During 'Niche formation', a niche matures to a degree that it may compete with the regime or provide viable 
solutions that may be absorbed by the regime. The literature on strategic niche management has identified the processes that are required for niche formation [31]:

1) The articulation of shared expectations and visions provides direction to learning processes, mobilizes actors, and legitimates (policy) support for the niche;

2) The involvement of actors and the building of social networks is important to create a value chain related to niche innovations and to provide the necessary resources (money, people, expertise);

3) Learning processes at multiple dimensions are required to advance the technology, to understand user preferences and develop markets, to probe the cultural and symbolic meaning of the niche innovation, to explore institutional arrangements that work, and to learn about (unintended) societal and environmental effects.

A policy strategy for niche formation should aim to support these different processes. Policy instruments for achieving this may include foresight exercises, targeted R\&D funding schemes, setting up of innovation platforms, demonstration projects, initiating joint learning processes involving producers and users, providing venture capital, relaxing regulation conditions for experiments, low-interest loans, educational policies and labour-market policies.

With 'Break-through' we refer to the stage when a niche innovation spreads beyond its initial niche through growing in terms of involved actors and market share, replication in other locations or contexts, linkage with related niche innovations, and transformation of regime level institutions and infrastructure [35]. A policy strategy for this stage should aim to improve the price-performance ratio of the niche innovation compared to established regime technologies, provide full access to infrastructure and markets, and remove institutional barriers. This includes amendment of legislation, market rules and technical standards that hamper the deployment of niche innovations, increasing societal awareness and acceptance, and the construction or retrofitting of infrastructure. ${ }^{8}$ Policy instruments for supporting the breakthrough of niche innovations may include public procurement, tax exemptions, feed-in tariffs, deployment subsidies, campaigns to spread knowledge and change societal values, and labelling to support the niche innovation. Furthermore, to reduce the influence of key regime actors on government, established actor-network structures need to be opened up. This may involve the development of new forums to bypass traditional policy networks, and the balanced involvement of incumbent and niche actors in policy advisory councils.

\footnotetext{
${ }^{8}$ E.g., retrofitting of distribution grid to accommodate increasing shares of renewable electricity.
}

At the final stage, which we label as 'Market-based growth', the niche innovation has become fully price-competitive and specific supportive policy instruments (see above) are no longer required. To achieve competitiveness of renewable energy technologies, a policy strategy should withdraw support for and increase pressure on the energy regime through internalizing the environmental costs of carbon emissions to create an 'extended level playing field' on which niche innovations and the regime may compete [36]. Policy instruments may consist in the removal of (hidden) subsidies for fossil fuel-based technologies, $\mathrm{CO}_{2}$ pricing, pollution taxes or even banning certain technologies. Actor networks will be further restructured, and former niche actors develop close relationships with policy makers and regulators. Note that market shares of (former) niche innovations may still grow considerably at this stage. A policy strategy for this stage should also aim to remove or reduce unintended side-effects ${ }^{9}$ and to withdraw subsidies and other policy instruments that induce societal costs.

\section{Differences between model assumptions and characteristics of the MENA region}

The phase model which serves as a starting point in this article (called $P M G$-Phase Model Germany-from here on) has been developed for the German context, which results in particular model assumptions (see "The starting point: the phase model for the German energy transition"). Several differences exist between those model assumptions and characteristics of MENA countries, which require consideration in the phase model for MENA countries developed in this article. The differences are outlined in the following, and integrated into the phase model in "Adaptation of model assumptions to characteristics of MENA countries".

\section{Development of energy demand}

Contrary to the future decrease in primary energy demand assumed in the PMG, MENA countries experience strong increases in energy demand, which are also expected to continue with higher rates than in the global average in the future. For example, BP [37] projects an increase of energy demand of around 2\% per annum in the Middle East which leads to a 55\% growth in energy consumption until 2040. The final energy consumption is expected to further increase mainly in the power sector, the industrial sector and the non-combusted sector. One important driver is population growth. Population is expected to increase in countries such as Egypt, Iraq and Sudan by about 26 million, 17 million

\footnotetext{
${ }^{9}$ For example, the removal of distributional effects, i.e., the burden should be shared in a fair manner among society.
} 
and 16 million people, respectively, between 2015 and 2030 [38]. Energy intensity may decline by $11 \%$ over the period 2017-40 in the Middle East, but this is much less than in the global average [37]. The use of energy is highly inefficient in several application areas due to low insulation quality of buildings [39] but also technical inefficiencies in the existing infrastructures [40]. For example, the losses of electricity in distribution are between 11 and $15 \%$ in stable MENA countries in comparison to $4 \%$ in Germany [41]. Moreover, the increase in demand is intensified as the installation of energy-intensive seawater desalination capacities is part of many regional strategies to meet the extreme water scarcity that the Mashreq countries are confronted with. Consequently, the total electricity demand for seawater desalination is predicted to triple in MENA by 2030 compared to the 2007 level [42].

\section{Potential for renewable energy generation}

While in the later phases 3 and 4, the PMG expects imports of renewables-based energy (electricity, hydrogen, synthetic fuels), this might be different in the MENA countries. The region is endowed with rich renewable energy resources [43] with an estimated potential of renewables which is far bigger than the expected regional demand [44-46]. Although those potentials are hardly tapped up to now, ${ }^{10}$ the region could become self-sufficient with or even a net-exporter of renewables-based energy in the future.

\section{The role of hydrogen and synthetic fuels/gases}

In the longer term, the large economic potential of solar and wind energy in MENA countries also potentially gives them the opportunity to export renewables-based energy carriers to neighboring regions such as Europe. The interest of European countries in energy imports based on energy carriers such as hydrogen is growing and respective strategies are being developed. ${ }^{11}$ Different technological pathways for the production of synthetic fuels are being currently researched ${ }^{12}$ [47-49], and today it is not clear which parts of a value chain for their production will be located in which region/country. Some resource-rich countries in MENA have already developed infrastructures for gas and oil and are experienced in the production and handling of gas and liquid fuels. These countries might benefit from the creation of

\footnotetext{
${ }^{10}$ In the Middle East, primary energy supply by wind and solar was 564 ktoe in 2017, while in the same year natural gas provided 418.173 ktoe and oil provided 322.644 ktoe. https://www.iea.org/ regions/middle-east (last accessed: June 2020).

${ }^{11}$ See for example: https://dii-desertenergy.org/the-10th-desert-energ y-leadership-summit/ (last accessed: June 2020).

12 See for example: https://wupperinst.org/en/p/wi/p/s/pd/789/(last accessed: June 2020)
}

synthetic fuel markets in later phases of the energy system transformation. Via power-to-X technology, oil producing and exporting countries might be able to organize a proactive switch from fossil fuel-based to renewable energy-based products while still using existing infrastructures, i.e., existing assets. To this aim, the existing natural gas and fossil fuel infrastructure might be retrofitted for large-scale transmission and storage of renewables-based synthetic gases and fuels.

\section{State of the electricity infrastructure}

While the PMG assumes a fully developed national and cross-border electricity grid, the electricity systems in the MENA region are still under development. For enabling feed-in of renewable electricity, the access of renewable energy plants to the grid needs to be facilitated and regulated, but technical codes that define requirements and standards for PV and wind power plants are lacking in many countries of the region [50]. Clear and consistent regulations need to be developed for grid access to encourage investments into renewables, but such regulations exist in only a few countries in the region [51]. Furthermore, in order to accommodate high shares of fluctuating renewables, the electricity grid requires considerable intrastate extension as well as cross-border expansion and integration. However, physical interconnections between countries exist only in regional clusters and actual power exchange remains on a modest level, in general [52]. A harmonized regulatory framework for electricity trade is absent in the region.

\section{Competitiveness of renewable energy technology}

Since 2010, the costs for PV modules have fallen by around $80 \%$, while wind turbine prices have fallen by $30-40 \%$ since 2009, and renewables have become the lowest-cost source of new power generation in most parts of the world [53]. Supportive technologies such as battery storage have also been developed and advanced globally in the recent decade(s). While the PMG assumes that renewable energy technologies initially need time for maturation, this assumptions seems no longer appropriate. Instead, MENA countries can and do already benefit from experiences made and cost reductions achieved through global technology development. Furthermore, a global network of companies has emerged around renewable energy technologies, which can potentially be tapped to provide expertise for the implementation and operation of renewable energy technology in MENA countries. 
Fig. 2 Overview of transformation phases and stages of innovation clusters

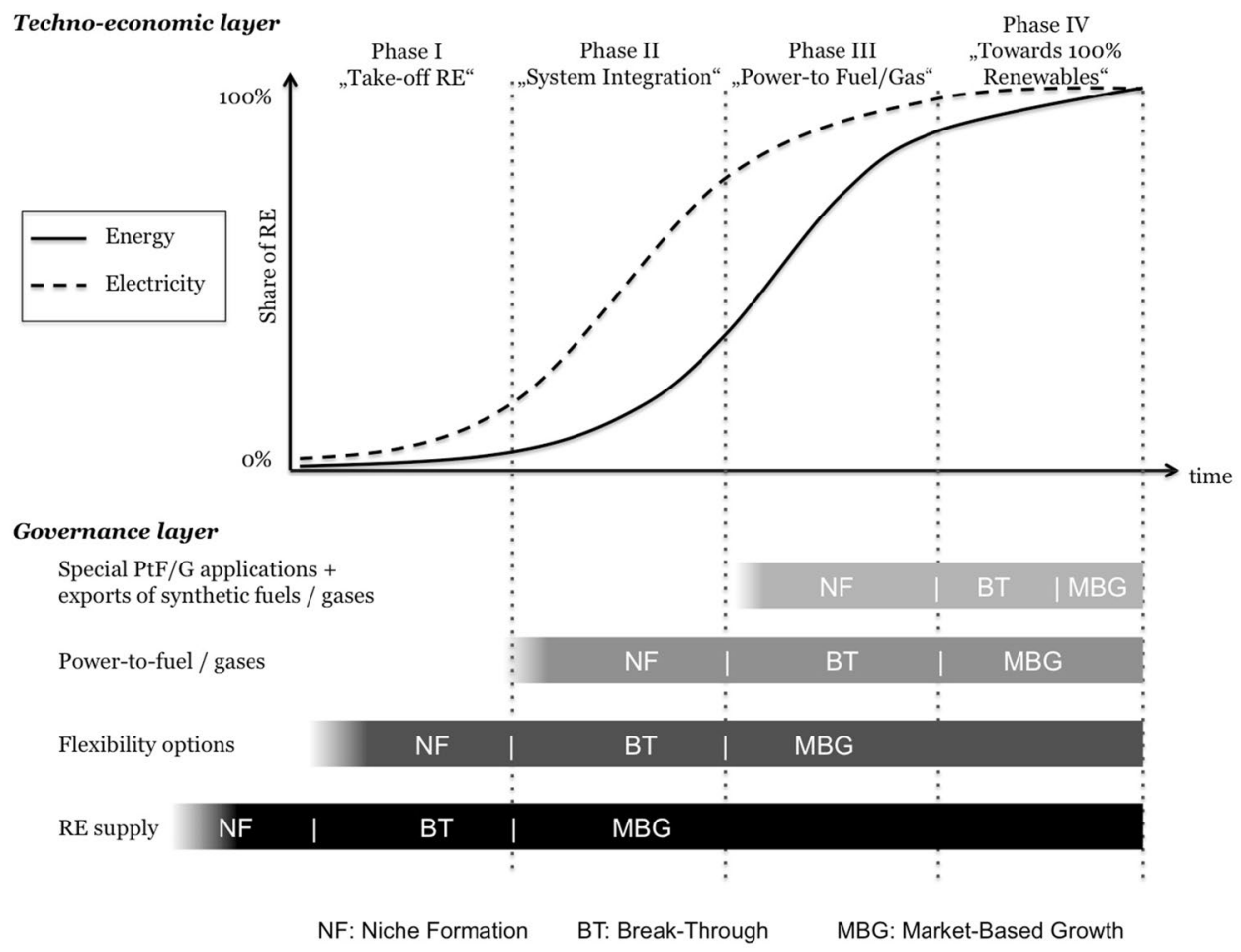

\section{A phase model for the MENA region}

In this section, the building blocks presented in "Building blocks of the phase model for MENA countries"- the four phases of the phase models for the German energy transition; insights concerning the governance of transitions condensed into three different stages; differences between model assumptions and the characteristics of the MENA regionwill be integrated into a phase model for energy transitions towards renewables-based low-carbon energy systems in MENA countries (see below: Fig. 2, Tables 2 and 3).

\section{Integration of transition phases and governance stages}

We assume that the overall logic of the original phase model presented in "The starting point: the phase model for the German energy transition" also holds for MENA countries, and therefore adopt the four transition phases suggested by $[10,11]$, labelling them as follows: 'Take-off RE', 'System integration', 'Power-to-Fuel/Gas', 'Towards 100\% Renewables'.

Each of these phases is characterized by the break-through and up-scaling of a specific cluster of innovations: for phase 1 these are the renewable electricity (RE) technologies, for phase 2 the flexibility options, for phase 3 the power-to-gas/ fuel technologies and for phase 4 technologies for sectors that are difficult to decarbonize such as specific industries and aviation. The synthesis of insights about transition governance presented in "Governing transitions: insights from sustainability transitions research" reveals that the break-through of each innovation cluster is dependent on niche-formation processes in the previous phase, and governance measures that support the break-through and upscaling in the current phase. The respective innovation cluster then continues to spread through market-based growth in later phases.

Following these considerations and in order to link phases of the PMG and the governance stages outlined in "Three stages of transitions: niche formation, break-through and market-based growth", each phase is formally associated with the break-through stage of the innovation cluster that shapes this phase. The niche-formation stage is assumed to take place in the previous phase, and market-based growth continues in all subsequent phases. ${ }^{13}$

The changing deployment of technologies across markets will be captured in a 'techno-economic layer' [54] of our phase model, which closely resembles the structure of the PMG. To represent the governance stages, we add a 'governance layer'. This layer connects the developments of the techno-economic energy system as outlined in the

\footnotetext{
13 The conceptual underpinning of this approach with regard to transition theory is based on the MLP being a conceptual framework that can be applied to different empirical levels [30]. We conceptually split up the overall energy transition into four 'smaller' transitions around innovation clusters that each dominate one of the four phases. We then apply the MLP and associated suggestions for transition governance to each of these four 'smaller' transitions.
} 
Table 1 Stages of the niche innovation journey and associated classes of governance measures

\begin{tabular}{ll}
\hline Stage & Classes of governance measures \\
\hline Niche formation & Support the development of shared expectations and visions \\
& Build actor networks around innovation clusters (including empowerment of actors) \\
& Support learning processes to integrate globally available technologies into the domestic energy \\
& system and assess local potentials \\
Break-through & Provide full access to infrastructure and markets, including the removal of institutional barriers \\
& Support broad adoption of the niche innovations \\
Market-based growth & Put pressure on regime technology \\
& Withdraw support for (former) niche innovations \\
& Reduce unintended side-effects \\
\hline
\end{tabular}

techno-economic layer to governance approaches which the transition governance literature suggests for fostering those techno-economic developments. Figure 2 depicts the resulting overall transition dynamics across all four phases, including governance stages for the different innovation clusters.

The literature on transition governance briefly outlined and synthesized above in "Governing transitions: insights from sustainability transitions research" highlights the relevance of a diversity of measures and of their appropriate timing in the transition process. It also provides a wealth of examples for such measures. We classify the multitude of possible measures outlined in "Three stages of transitions: niche formation, break-through and market-based growth" broadly along the three stages of the governance layer: 'niche formation', 'break-through' and 'market-based growth' as shown in Table 1.

The list of classes of governance measures proposed in Table 1 is coarse. No specific measures are included as the 'best' mix of concrete policies needs to be found for each individual country and situation. The purpose of adding the classification of measures to the phase model is rather to support reflexivity about governance aims in different phases of the transition.

\section{Adaptation of model assumptions to characteristics of MENA countries}

The incorporation of differences between the assumptions underlying the $P M G$ and the characteristics of MENA countries identified in "Differences between model assumptions and characteristics of the MENA region" results in a number of adaptations of the phases compared to the PMG:

- The expected increase in overall energy demand of MENA countries ("Development of energy demand") provides room in phases 1 and 2 for the establishment of renewables and for increasing their feeding volume considerably without immediately undermining the existing business of fossil fuel- and natural gas-providing industries.
- The potential for renewable energy generation in the MENA region ("Potential for renewable energy generation") provides ample opportunities to satisfy growing domestic demand and for future renewables-based energy exports, potentially making use of retrofitted existing natural gas and fossil fuel infrastructures ("The role of hydrogen and synthetic fuels/gases"). Hence, while the PMG foresees an important role for imports of renewables-based energy carriers in phases 3 and 4 , it will be considered for MENA countries that domestic demand for synthetic fuels and gases can be satisfied based on domestic renewable energy throughout all phases, and that exports of renewables based synthetic fuels and gases becomes an economic opportunity in phase 4 .

- The state of the infrastructure in MENA countries ("State of the electricity infrastructure") implies that higher emphasis needs to be put on grid retrofitting and expansion.

- The competitiveness of renewable energy and the expected future lag of energy transitions in MENA countries compared to global front-runner countries ("Competitiveness of renewable energy technology") provide the opportunity to speed-up the stage of niche formation in all phases of the transition. Niche formation processes are, however, still needed to internalize globally existing knowledge domestically, to develop institutions that support niche innovations but at the same time fit into the countries' institutional structure, and to build up actor networks including domestic and international actors.

\section{The phase model}

Tables 2 and 3 summarize the phase model which results from the previous considerations. Table 2 presents the developments on the techno-economic layer while Table 3 focusses on the governance layer. ${ }^{14}$

\footnotetext{
14 The figures for 'RE share in energy system about ...' given in the Tables 2, 3 can be seen as indicative since there is no strong crossover from one phase to the other. It is rather a fluent transition.
} 
Table 2 Techno-economic layer of the phase model

\begin{tabular}{|c|c|c|c|}
\hline $\begin{array}{l}\text { Phase I } \\
\text { "Take-off RE" }\end{array}$ & $\begin{array}{l}\text { Phase II } \\
\text { "System integration" }\end{array}$ & $\begin{array}{l}\text { Phase III } \\
\text { "Power-to fuel/gas (PtF/G)" }\end{array}$ & $\begin{array}{l}\text { Phase IV } \\
\text { "Towards } 100 \% \text { renewable" }\end{array}$ \\
\hline $\begin{array}{l}\text { RE share in energy system about } \\
0-20 \%\end{array}$ & $\begin{array}{l}\text { RE share in energy system about } \\
20-50 \%\end{array}$ & $\begin{array}{l}\text { RE share in energy system about } \\
50-80 \%\end{array}$ & $\begin{array}{l}\text { RE share in energy system about } \\
80-100 \%\end{array}$ \\
\hline $\begin{array}{l}\text { Market introduction of RE draw- } \\
\text { ing on globally available technol- } \\
\text { ogy and driven by global price } \\
\text { drop of RE } \\
\text { Extension and retrofitting of elec- } \\
\text { tricity grid } \\
\text { No replacement of fossils due to } \\
\text { growing markets }\end{array}$ & $\begin{array}{l}\text { Further grid extension (national } \\
\text { and international) } \\
\text { ICT structures integrated with } \\
\text { energy systems (e.g., introduc- } \\
\text { tion of smart meters) } \\
\text { System penetration of flexibility } \\
\text { options (e.g., battery storage) } \\
\text { Direct electrification of applica- } \\
\text { tions in the sectors buildings, } \\
\text { mobility and industry, and } \\
\text { changing business models in } \\
\text { those sectors (e.g., heat pumps, } \\
\text { e-cars, smart-home systems, } \\
\text { marketing of load shedding of } \\
\text { industrial loads) } \\
\text { No replacement of fossils due to } \\
\text { growing markets }\end{array}$ & $\begin{array}{l}\text { Temporarily high negative } \\
\text { residual loads due to high shares } \\
\text { of RE } \\
\text { Extension of long-term storages } \\
\text { (e.g., storage of synthetic gas) } \\
\text { Increasing volumes of PtF/G in } \\
\text { transport, substitute for fossil } \\
\text { fuels and natural gas } \\
\text { First PtF/G infrastructure is } \\
\text { built-up (satisfying upcoming } \\
\text { national/foreign demand) } \\
\text { Sales volumes of fossils start to } \\
\text { shrink } \\
\text { Existing fossil-based business } \\
\text { models start to change }\end{array}$ & $\begin{array}{l}\text { Full replacement of fossils by RE } \\
\text { and RE-based fuels } \\
\text { Large-scale built-up of infrastruc- } \\
\text { ture for PtF/G exports } \\
\text { Stabilization of PtF/G business } \\
\text { models and production capaci- } \\
\text { ties (large-scale investments) } \\
\text { Consolidation of RE-based export } \\
\text { models } \\
\text { Phase-out of fossil fuel infrastruc- } \\
\text { tures and business models }\end{array}$ \\
\hline \multicolumn{4}{|c|}{ Continuing improvement of efficiency } \\
\hline
\end{tabular}

As in the phase model presented in "The starting point: the phase model for the German energy transition", throughout all phases, the capacities for renewable electricity supply are expanded to meet increasing demands, including demand from other sectors and from power-to-fuel/gas applications as well as - in later phases_-exports. Furthermore, energy efficiency needs to be increased considerably throughout all the phases. ${ }^{15}$

\section{Discussion and conclusions}

Starting from the hypothesis that a conceptual framework for describing energy transitions towards renewables-based lowcarbon energy systems in MENA countries is a prerequisite for fostering and steering such transitions, a phase model was developed. To develop the model, we built upon a phase model that has been developed for Germany, complemented it by insights about transition governance, and adapted it to capture differences between its underlying assumptions and characteristics of the MENA region.

The resulting proposed phase model for energy transitions in MENA countries includes four subsequent phases ("Take-off RE”, "System integration", "Power-to-Fuel/Gas", "Towards $100 \%$ Renewable"), each of which is characterized

\footnotetext{
15 The role of energy efficiency for successful transitions to low-carbon energy systems is paramount. However, it is beyond the scope of this article to provide a detailed discussion thereof.
}

by a different cluster of innovations that shapes the respective phase. These innovation clusters each enter the system via three "stages" of development ("Niche formation", "Break-through", "Market-based growth") which describe different levels of maturity and market penetration of the innovations, and which require appropriate governance. Suggestions for governance measures are made along general lines.

This article and the presented phase model make the following contributions to the scientific literature of energy transitions in the MENA region: the phase model presented by Fischedick et al. [10] and Henning et al. [11], which was originally published in German, only, is made available for an international audience. Their techno-economic perspective on energy system transformations is furthermore combined with insights about the dynamics of long-term fundamental change of societal subsystems and their governance into an extended phase model that distinguishes a techno-economic layer and a governance layer to provide a richer picture. Finally, the adaptation of the model to the MENA region is another original contribution of this study.

From a practitioner's perspective, the phase model has the potential to support strategy development and governance of energy transitions in MENA countries in two complementary ways: the techno-economic layer of the model provides clear (intermediate) targets for system development as orienting guidelines for decision-makers. The governance layer adds some guidance as to which governance approaches are supportive for the achievement of those targets. 


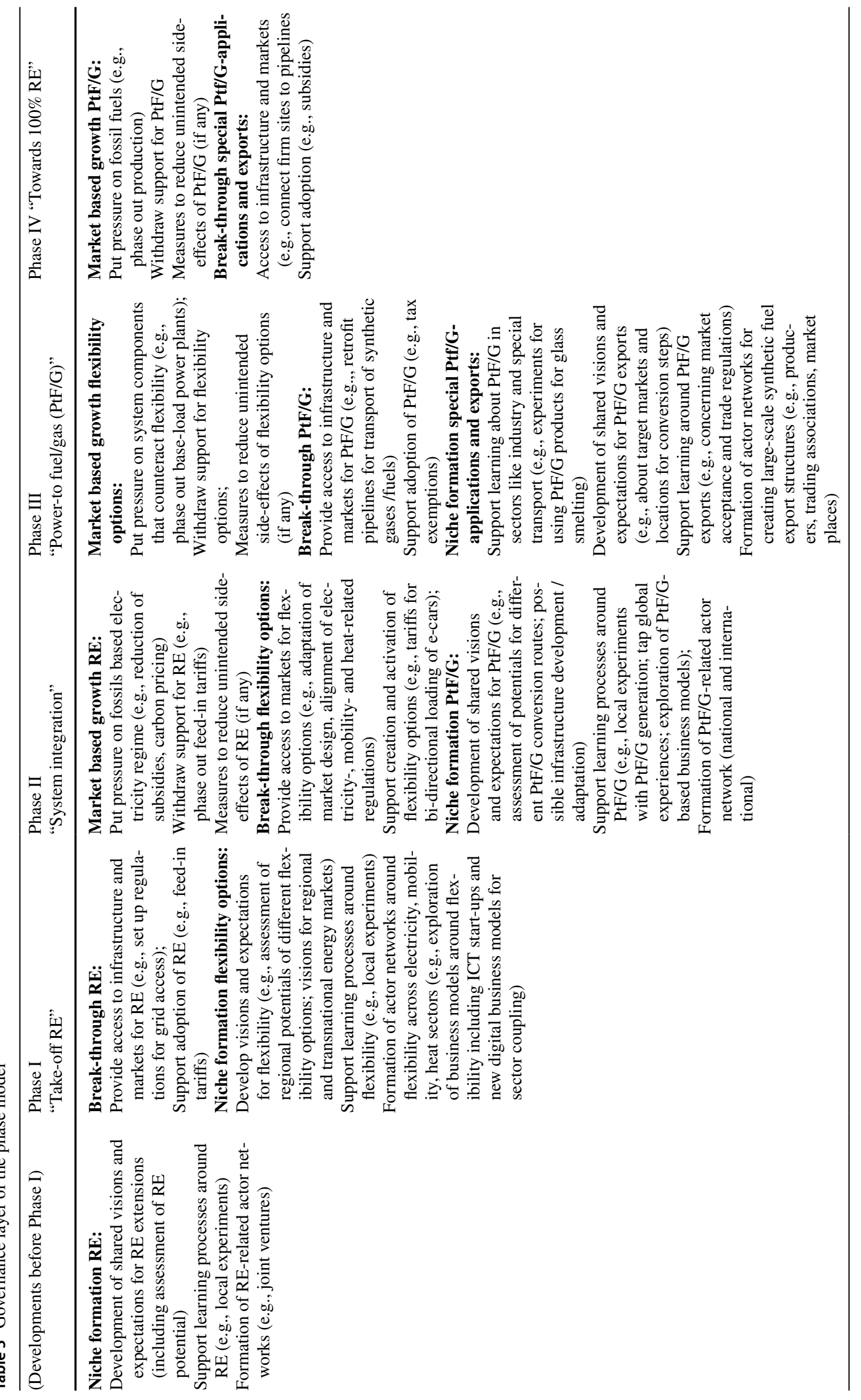


Although the developments sketched in the phase model seem plausible in the humble views of the authors, the phase model should not be confused with a prediction of how a transition unfolds, nor does it provide a bullet-proof 'recipe' for managing a transition. Its purpose is to support governance through facilitating long-term planning across different domains especially in the MENA region.

An exploratory application of an earlier version of the phase model to Jordan was conducted, ${ }^{16}$ which cannot be reported here at length for reasons of space. This study was discussed with high-ranking policy-makers, representatives from science, industry and civil society from Jordan and scientists from Morocco and Tunisia. Based on these experiences, we conclude that the model is useful to structure the many on-going developments in Jordan's energy system, and to provide insights into necessary next steps to transform Jordan's energy system into a renewables-based system. As such, we claim that the presented phase model fulfils its purpose and can be used to support discussions about strategies and policy-making.

Acknowledgements The study on which this article is based was financially supported by the Friedrich-Ebert- Stiftung Jordan and Iraq. The authors thank the Friedrich-Ebert-Stiftung Jordan and Iraq for agreeing to the publication of the study in the journal "Energy Transitions". The authors furthermore thank the reviewer for helpful comments and suggestions.

Open Access This article is licensed under a Creative Commons Attribution 4.0 International License, which permits use, sharing, adaptation, distribution and reproduction in any medium or format, as long as you give appropriate credit to the original author(s) and the source, provide a link to the Creative Commons licence, and indicate if changes were made. The images or other third party material in this article are included in the article's Creative Commons licence, unless indicated otherwise in a credit line to the material. If material is not included in the article's Creative Commons licence and your intended use is not permitted by statutory regulation or exceeds the permitted use, you will need to obtain permission directly from the copyright holder. To view a copy of this licence, visit http://creativecommons.org/licenses/by/4.0/.

\section{References}

1. UNFCCC secretariat: NDC registry. https://www4.unfccc.int/sites /NDCStaging/Pages/All.aspx. Accessed June 2020

2. Mirkin, B.: Population levels, trends and policies in the Arab region: challenges and opportunities. United Nations Development Programme, New York (2010)

3. Menichetti, E., El-Gharras, A., Duhamel, B., Karbuz, S.: The MENA Region in the Global Energy Markets. MENARA Working Papers. (2018)

4. Grin, J., Rotmans, J., Schot, J.: Transitions to sustainable development: new directions in the study of long term transformative change. Routledge, Abingdon (2010)

5. IEA: Energy and climate change. OECD/IEA, Paris (2015)

16 https://library.fes.de/pdf-files/bueros/amman/15492.pdf (last accessed: June 2020)
6. OECD: System innovation: synthesis report. OECD, Paris (2015). Available at: http://www.pte.pl/pliki/2/1/OECD\%20System.pdf. Accessed June 2020

7. Weber, K.M., Rohracher, H.: Legitimizing research, technology and innovation policies for transformative change: combining insights from innovation systems and multi-level perspective in a comprehensive 'failures' framework. Res. Policy 41, 1037-1047 (2012)

8. Loorbach, D.: Transition management: new mode of governance for sustainable development. International Books, Utrecht (2007)

9. Voß, J.-P., Smith, A., Grin, J.: Designing long-term policy: rethinking transition management. Policy Sci. 42, 275-302 (2009)

10. Fischedick, M., Samadi, S., Hoffmann, C., Henning, H.-M., Pregger, T., Leprich, U., Schmidt, M.: Phasen der Energisystemtransformation. FVEE, Berlin (2014)

11. Henning, H.-M., Palzer, A., Pape, C., Borggrefe, F., Jachmann, H., Fischedick, M.: Phasen der Transformation des Energiesystems, 65th edn. Energiewirtschaftliche Tagesfragen, Berlin (2015)

12. BP: BP Energy Outlook-2018 edition. BP energy economics (2018). Available at: https://www.bp.com/en/global/corporate/ energy-economics/energy-outlook.html. Accessed June 2020

13. IEA: World energy outlook 2017. International Energy Agency, Paris (2017)

14. Papaefthymiou, G., Haesen, E., Sach, T.: Power system flexibility tracker: indicators to track flexibility progress towards high-RES systems. Renew. Energy 127, 1026-1035 (2018)

15. IRENA: Adapting market design to high shares of variable energy. International Renewable Energy Agency, Abu Dhabi (2017)

16. Lechtenböhmer, S., Schneider, C., Samadi, S.: Energy efficiency quo vadis?: The role of energy efficiency in a $100 \%$ renewable future. In: ECEEE Summer Study Proceedings (2017)

17. Samadi, S., Terrapon-Pfaff, J., Lechtenböhmer, S., Knoop, K.: Long-term low greenhouse gas emission development strategies for achieving the $1.5^{\circ} \mathrm{C}$ target-insights from a comparison of German bottom-up energy scenarios. Carbon Manag. 9, 549-562 (2018)

18. Elsner, P., Fischedick, M., Sauer, D.U.: Flexibilitätskonzepte für die Stromversorgung 2050: Technologien-Szenarien-Systemzusammenhänge. Nationale Akademie der Wissenschaften Leopoldina, Halle (2015)

19. Markard, J.: The next phase of the energy transition and its implications for research and policy. Nat Energy 3, 628-633 (2018)

20. Hoogma, R., Weber, M., Elzen, B.: Integrated long-term strategies to induce regime shifts towards sustainability: the approach of strategic niche management. Towards environmental innovation systems, pp. 209-236. Springer, Berlin (2005)

21. IPCC.: Summary for Policymakers. In: Global Warming of $1.5^{\circ} \mathrm{C}$. An IPCC Special Report on the impacts of global warming of $1.5^{\circ} \mathrm{C}$ above pre-industrial levels and related global greenhouse gas emission pathways, in the context of strengthening the global response to the threat of climate change, sustainable development, and efforts to eradicate poverty. World Meteorological Organization, Geneva (2018)

22. Markard, J., Raven, R., Truffer, B.: Sustainability transitions: an emerging field of research and its prospects. Res. Policy 41, 955-967 (2012). https://doi.org/10.1016/j.respol.2012.02.013

23. Smith, A., Voß, J.-P., Grin, J.: Innovation studies and sustainability transitions: the allure of the multi-level perspective and its challenges. Res. Policy 39, 435-448 (2010). https://doi. org/10.1016/j.respol.2010.01.023

24. Geels, F.W.: Technological transitions as evolutionary reconfiguration processes: a multi-level perspective and a case-study. Res. Policy 31, 1257-1274 (2002). https://doi.org/10.1016/S0048 $-7333(02) 00062-8$ 
25. Geels, F.W., Sovacool, B.K., Schwanen, T., Sorrell, S.: Sociotechnical transitions for deep decarbonization. Science 357, 1242 1244 (2017)

26. Rip, A., Kemp, R.: Technological Change. In: Rayner, S., Malone, E.L. (eds.) Human choice and climate change-resoures and technology. Batelle Press, Columbus (1998)

27. Unruh, G.C.: Understanding carbon lock-in. Energy Policy 28, $817-830(2000)$

28. Geels, F.W., Schot, J.: Typology of sociotechnical transition pathways. Res. Policy 36, 399-417 (2007). https://doi.org/10.1016/j. respol.2007.01.003

29. Geels, F.W., Kern, F., Fuchs, G., Hinderer, N., Kungl, G., Mylan, J., Neukirch, M., Wassermann, S.: The enactment of socio-technical transition pathways: a reformulated typology and a comparative multi-level analysis of the German and UK low-carbon electricity transitions (1990-2014). Res. Policy 45, 896-913 (2016)

30. Geels, F.W.: The multi-level perspective on sustainability transitions: responses to seven criticisms. Environ. Innov. Soc. Transit. 1, 24-40 (2011). https://doi.org/10.1016/j.eist.2011.02.002

31. Schot, J., Geels, F.W.: Strategic niche management and sustainable innovation journeys: theory, findings, research agenda, and policy. Technol. Anal. Strateg. Manag. 20, 537-554 (2008)

32. Kivimaa, P., Kern, F.: Creative destruction or mere niche support? innovation policy mixes for sustainability transitions. Res. Policy 45, 205-217 (2016)

33. David, M.: Moving beyond the heuristic of creative destruction: targeting exnovation with policy mixes for energy transitions. Energy Res. Soc. Sci. 33, 138-146 (2017)

34. Rotmans, J., Kemp, R., Van Asselt, M.: More evolution than revolution: transition management in public policy. Foresight 3, 15-31 (2001)

35. Naber, R., Raven, R., Kouw, M., Dassen, T.: Scaling up sustainable energy innovations. Energy Policy 110, 342-354 (2017)

36. van den Bergh, J.C., Faber, A., Idenburg, A.M., Oosterhuis, F.H.: Survival of the greenest: evolutionary economics and policies for energy innovation. Environ. Sci. 3, 57-71 (2006)

37. BP: BP Energy Outlook-2019 edition. BP energy economics (2019). Available at: https://www.bp.com/en/global/corporate/ energy-economics/energy-outlook.html. Accessed June 2020

38. UNICEF: MENA generation 2030-investing in children and youth today to secure a prosperous region tomorrow. United Nations Children's Fund, Washington (2019)

39. Meir, I.A., Peeters, A., Pearlmutter, D., Halasah, S., Garb, Y., Davis, J.-M.: An assessment of regional constraints, needs and trends. Adv. Build. Energy Res. 6, 173-211 (2012)

40. The World Bank: Delivering energy efficiency in the middle east and North Africa-achieving energy efficiency potential in the industry, Services and Residential Sectors. International Bank for Reconstruction and Development, Washington (2016)

41. The World Bank.: Electric power transmission and distribution losses (\% of output). https://data.worldbank.org/indicator/ EG.ELC.LOSS.ZS. Accessed June 2020

42. IEA-ETSAP, IRENA: Water desalination using renewable energy. International Renewable Energy Agency (IRENA), Abu Dhabi (2012)

43. IRENA: Pan-Arab renewable energy strategy 2030. International Renewable Energy Agency (IRENA), Abu Dhabi (2014)

44. Deng, Y.Y., Haigh, M., Pouwels, W., Ramaekers, L., Brandsma, R., Schimschar, S., Grözinger, J., de Jager, D.: Quantifying a realistic, worldwide wind and solar electricity supply. Global Environ. Change 31, 239-252 (2015)

45. DLR.: Concentrating solar power for the Mediterranean Regionfinal report. Deutsches Zentrum für Luft- und Raumfahrt e.V. (DLR), Stuttgart, Germany (2005)

46. Edenhofer, O., Pichs-Madruga, R., Sokona, Y.: IPCC special report on renewable energy sources and climate change mitigation. Cambridge University Press, Cambridge (2012)

47. Fasihi, M., Bogdanov, D., Breyer, C.: Long-term hydrocarbon trade options for the Maghreb Region and Europe-renewable energy based synthetic fuels for a net zero emissions world. Sustainability 9, 306 (2017). https://doi.org/10.3390/su9020306

48. Timmerberg, S., Kaltschmitt, M.: Hydrogen from renewables: supply from North Africa to Central Europe as blend in existing pipelines-potentials and costs. Appl. Energy 237, 795-809 (2019). https://doi.org/10.1016/j.apenergy.2019.01.030

49. Trop, P., Goricanec, D.: Comparisons between energy carriers' productions for exploiting renewable energy sources. Energy. 108, 155-161 (2016). https://doi.org/10.1016/j.energy.2015.07.033

50. RCREEE: Integrating renewable energy projects into grids: technical requirements guideline. Regional Center for Renewable Energy and Energy Efficiency (RCREEE), Cairo (2017)

51. RCREEE: Arab future energy Index 2015-renewable energy. Regional Center for Renewable Energy and Energy Efficiency (RCREEE), Cairo (2015)

52. The World Bank: Integration of electricity networks in the Arab World-regional market structure and design. The World Bank, Washington (2013)

53. IRENA: Renewable power generation costs in 2018. International Renewable Energy Agency, Abu Dhabi (2019)

54. Cherp, A., Vinichenko, V., Jewell, J., Brutschin, E., Sovacool, B.: Integrating techno-economic, socio-technical and political perspectives on national energy transitions: a meta-theoretical framework. Energy Res. Soc. Sci. 37, 175-190 (2018) 